\title{
Controversies in Science and Technology_A Protocol for Comparative Research
}

By: Gerald E. Markle and James C. Petersen

Department of Sociology Western Michigan University Kalamazoo, MI 49008

Markle, Gerald E. and James C. Petersen. "Controversies in Science and Technology: A Protocol for Comparative Research," Science, Technology and Human Values, Winter, 1981, 6: 25-30.

Made available courtesy of Sage Publications Ltd: http://sth.sagepub.com/

***Note: Figures may be missing from this format of the document

The case study method has dominated scholarly examination of scientific and technical controversies, largely because the approach provides great richness of detail about particular features of a controversy. However, case studies in scientific controversies should be viewed not only as unique products but also as strategic research sites that may guide the development of theory. For example, controversies in science and technology frequently involve challenges to existing political arrangements or calls for new public policy. Since controversies are generally played out within an adversarial framework, the disputes are easily analyzed along the strengths and weaknesses of opposing arguments. ${ }^{1}$ From the sociological perspective, the dynamics of controversy may reveal ". . special interests, vital concerns, and hidden assumptions of the various actors". ${ }^{2}$ In a broader sense, the study of controversies may shed light on the internal and external dynamics of science itself ${ }^{3}$ and focus attention on patterns of interaction between internal and external factors. Finally, the controversies may be seen as models of disputes in society and thus relevant to understanding social conflict and social change.

Individual case studies, especially if well chosen, can contribute greatly to our understanding of the processes by which controversies in science and technology emerge, develop, and are resolved. But nowhere in the literature on scientific or technical controversies have researchers attempted systematically to analyze large numbers of cases. ${ }^{4}$ Most studies in this field are, in fact, analyses of single cases. ${ }^{5}$

Attempting to use case studies developed by other researchers poses problems of comparison and generalization, however, because different researchers employ different conceptual frameworks and approaches to their data. ${ }^{6}$ Development of a common research protocol for case study analyses of controversies in science and technology would greatly facilitate future comparative research aimed at developing generalizations about these disputes and their resolution. Such a protocol might also guide retrospective analyses of existing data. ${ }^{7}$

Recognition of the need to systemize and standardize secondary data for science studies is not new. In his "Episodic Memoir," Robert Merton ${ }^{8}$ recounts the efforts of Charles Gillespie to develop a research protocol for the sociology of science. The plan was for contributors to the Dictionary of Scientific Biography (DSB) to complete a research schedule while collecting data for biographical articles. Merton reported that the sponsor greeted the plan with ambivalence and the project was dropped so as not to jeopardize the $D S B$. 
As an initial step toward a research protocol, we offer the following list of questions which we see as critical in understanding controversies in science and technology. Our approach has been heavily influenced by Bloor's 9 call for the "strong program" in the sociology of knowledge. Bloor contends that the sociology of scientific knowledge should be causal, impartial, and symmetrical. While we would not want to argue that social factors are the sole cause of beliefs, scholars should be concerned with the social factors producing beliefs or states of knowledge. Furthermore, the strong program demands an approach which is "impartial with respect to truth and falsity, rationality or irrationality, success or failure". ${ }^{10}$ Explanations should be symmetrical; the same types of cause may explain true or false beliefs. As Bloor has observed, scholars of science have too frequently sought causes to explain error or deviation while assuming that logic, rationality, and truth were their own explanation.

In addition, we have been influenced by the movement to study the political sociology of science." We have found Schattschneider's emphasis on the socialization and expansion of conflict in disputes and Gamson's ${ }^{12}$ analysis of influence and social control especially useful in developing the protocol. In our work on the Laetrile controversy, ${ }^{13}$ we have examined the political aspects of the dispute along with other value claims. In addition we have considered knowledge claims made by both Laetrile advocates and opponents.

\section{NOTES ON THE PROTOCOL}

Following Bloor, and at the same time considering the practical needs of the researcher, our protocol sets forth a series of questions which are dominantly empirical, materialistic, behavioral, and agnostic. Questions call for relatively simple distinctions, emphasizing the quantitative. We recognize the dangers of making simple distinctions about a complex world, but creating a large set of categorical data should facilitate comparative, even statistical analysis. Our questions emphasize the materialistic aspects of controversy; for example, our interest is more with how religious doctrine is used as strategy and tactic rather than with interpretation of the doctrine itself. The protocol is behavioral, in part because questions about motivation, interpersonal relationships, etc., are not easily answerable from archival material and in part because the dynamics of controversy are most immediately shaped by what people do rather than what they feel. Finally, our interest is not to crown winners or blame losers, but rather to understand how victory or defeat develops as conflicts are resolved. In taking an agnostic position we ask the same questions, whenever possible, of both sides, seeking to understand each side within the context of the other. The terminology is explicitly neutral, referring to "challengers" vs. "loyalists," "preservationists" vs. "innovators," etc., in any given controversy.

The protocol is organized into six major areas - overview, actors, strategy and tactics, knowledge claims, value claims, and resolution-each major section and sub-units having greater or lesser importance for a given controversy.

We begin a study of a controversy by examining its "shape," that is, its patterns of emergence, development, and resolution. Bibliometric and content analyses of scholarly, trade, and popular media are useful techniques here. Controversies in cancer research, ${ }^{14}$ for example, have been played out in different literatures; the dispute over estrogen-replacement therapy was covered heavily by the popular press; scores of articles in the trade press focused on the saccharin debate; and the controversy over fluorouracil was confined to the scholarly literature. 
We view individuals, organizations, and social movements as actors in any controversy. Our goal is to describe, both historically and demographically, these acting units. Clearly, in the controversy over Vitamin C and cancer, Linus Pauling is the crucial figure; formal organizations have done little to shape the dispute. In the dispute about estrogen-replacement therapy, on the other hand, the feminist movement has played a crucial role, and no individual leader has dominated the action.

Our categorization of strategy and tactics follows Gamson, ${ }^{15}$ the major advantage of which is that it facilitates explanation of the political nature of scientific and technical controversies. ${ }^{16}$

Both knowledge claims (IV) and value claims (V) shape scientific and technical controversies. ${ }^{17}$ Traditionally, sociology of science, as practiced in the United States, has been primarily concerned with the role of social or value factors in determining the behavior of scientists. More recently, sociologists of science, especially in Britain, have stressed the need to examine knowledge claims and the actual content of science. Sole reliance on either approach produces an incomplete picture of scientific controversies. What happens in a laboratory and in a court of law, for example, may not only be correlated, but may be interactive.

Our protocol concludes by assessing the resolution of the dispute. "Success," writes Gamson, "is an elusive idea." He continues:

What of the group whose leaders are honored or rewarded while their supposed beneficiaries linger in the same cheerless state as before? Is such a group more or less successful than another challenger whose leaders are vilified and imprisoned even as their program is eagerly implemented by their oppressor? Is a group a failure if it collapses with no legacy save inspiration to a generation that will soon take up the same cause with more tangible results? And what do we conclude about a group that accomplishes exactly what it set out to achieve and then finds its victory empty of real meaning for its presumed beneficiaries? ${ }^{18}$

Outcome is thus dependent on whether the challenger gains new advantage and whether the challenger gains acceptance (is seen as a valid spokesman for a legitimate set of interests). "Full response" (VI-A) indicates both while "collapse" (VI-D) indicates neither. "Cooptation" (VI-B) results from acceptance with no new advantage while "preemption" $(\mathrm{VI}-\mathrm{C})$ is the obverse: new advantage with no acceptance. The relationship of the four resolution categories is shown in Table I.

The following protocol obviously requires further refinement; it does, however, raise questions which seem central to understanding the processes by which controversies in science and technology emerge, develop, and are resolved. If we are to get beyond the stage of discussing the resolution of individual disputes, we must have a substantial data base on a broad range of controversies. And, only if the case studies making up this data set are comparable, will we be able to develop useful generalizations about the resolution of scientific and technical disputes.

\section{TABLE 1 IS OMITTED FROM THIS FORMATTED DOCUMENT}

\section{The Protocol}

I) Overview of the controversy A) Shape of the controversy

1) When did the challenge first originate? 


\section{2) Initial reaction:}

a) When was the first public reference to the Challengers?*

b) When was the first public rebuttal by the Loyalists?**

c) Did the controversy first emerge in the scientific literature, trade literature, or popular press?

3) What was the bibliometric shape (counts and content analyses) of the controversy:

a) in the scientific literature?

b) in the trade literature?

c) in the popular press?

4) What was the peak year(s) of the controversy?

5) Are there any public opinion polls? If so, what was the pattern of opinion?

6) When did the controversy end (i.e., was not present for more than 3 years):

a) in the scientific literature?

b) in the trade literature?

c) in the popular press?

8) Nature of the challenge and response

1) Were the Challengers or Loyalists:

a) pro- or anti-science?

b) pro- or anti-technology?

c) pro- or anti-expertise?

2) Were the Challengers' goals

a) big or little?

b) to be instituted immediately or in the future?

3) Was the challenge "preservationist" or "innovative"?**

C) Historical and cultural context

1) Did the controversy begin, peak, or end during:

a) peace or war?

b) stability or social turmoil?

c) business boom or depression?

2) What was the context of public opinion, in terms of:

a) evaluation of social institutions?

b) trust in leaders?

c) trends in liberalism or conservatism?

3) Was the controversy local, regional or national:

a) at the beginning of the dispute?

b) at the height of the dispute?

*The terms used for the opposing sides are chosen explicitly for a given controversy, e.g., "Preservationists" vs. "Innovators" or "" vs. "

**We posit an important difference between disputes where the Challenger is trying to introduce something new (e.g., Laetrile) and where the Challenger's goal is to remove a practice or product (e.g., estrogenreplacement therapy) from the system. The former challenges we term innovative, the latter, preservationist. 
4) Did the controversy arise from a discipline with:

a) slow or rapid growth?

b) single or competing paradigms?

II) Actors in the controversy

\section{A) Participation}

1) What was the role of experts at various stages of the controversy?

2) Was there participation by vested interests at various stages of the controversy?

3) What was the role of government officials at various stages of the controversy?

4) What was the role of the media at various stages of the controversy?

5) Was there citizen participation throughout the controversy?

B) Individuals

1 Was the leadership of the Challengers and the Loyalists:

a) charismatic?

b) one person or a small group?

c) experienced from previous science and technology disputes?

d) stable over time?

e) in possession of appropriate credentials?

2) What were the demographic (age, race, sex, etc.) and social (religious, economic, political, etc.) characteristics of
a) the leaders?
b) the participants?

C) Organizations/social movements

1) Are there any core organizations devoted exclusively to the aims of the Challengers or the Loyalists? If so, for each:
a) date founded?
b) by whom?
c) size?
d) type of organization: commercial, government or voluntary?
e) resources (e.g. income, expertise, media, etc.)?

2) Are there linkages or coalitions:

a) between core organizations?

b) to other organizations or groups?

*The key difference between constraints (M.A.1) and inducements (III.A.2) is that, in the former, disadvantage and, in the latter, advantage is added to the situation of authorities. In insulation (III.B.1), authorities contain the demands of Challengers by controlling entry into and exit from the social system. 
3) Are there peripheral organizations which have joined the dispute? If so, for each:

a) how did it get involved?

b) were its goals congruent with Challengers'?

c) type of organization?

d) resources?

e) size?

4) Was there an interested public (see I.A.5)?

III) Strategy and Tactics*

A) Did the Challengers use the following:

1) Constraints (e.g., demonstrations)?

2) Inducements (e.g., political contributions)? 3) Persuasion (e.g., education)?

B) Did the Loyalists use the following?

1) Insulation (e.g., gate-keeping)?

2) Sanctions (e.g., jailing)?

3) Persuasion (e.g., education)?

4) Participation (e.g., sharing decision-making)?

C) Was violence used by either side?

IV) Knowledge claims

A) Did the controversy focus on a specific claim or a large set of interrelated claims?

B) Did the Challengers or Loyalists advance a theoretical argument to state or support their positions?

C) Did Challengers or Loyalists do laboratory research or its equivalent to collect data?

D) Did Challengers or Loyalists posit benefit or risk to individuals or the environment?

E) Did Challengers or Loyalists specifically recognize and rebut claims made by the other side?

F) From the dominant paradigm of the time what was the strength of the Challengers' claim?

V) Value claims

A) Political/legal

1) Legislative: at the national, state or local level:

a) did existing legislation play a role?

b) did the Challengers or the Loyalists propose any new legislation? If yes, what was the outcome?

2) Elections: at the national, state or local level was the controversy an issue:

a) in an election? If yes, what was the outcome?

b) in a referendum? If yes, what was the outcome?

3) Administrative: at the national, state or local level were the Challengers or the Loyalists supported:

a) by executive actions

b) by bureaucratic (agency) actions?

4) Lobbying: were there paid or volunteer lobbyists for the Challengers or the Loyalists?

5) Did the Challengers or the Loyalists initiate any court actions? If yes,

a) what were the legal issues?

b) which courts were involved?

c) what kinds of actions (e.g., injunctions, personal injury suits) were initiated?

d) what was the outcome of each action?

B) Economics 


\section{1) Business}

a) Had any business invested in research or development? If yes, how much money was involved?

b) Did any business hold a relevant patent?

c) Was any business directly involved in selling the controversial product? If yes, what were its profits?

2) Advertising: how much money did the Challengers or the Loyalists spend in publicizing claims or positions? in which medium?

3) Research funding

a) Did government agencies support research by the Challengers or the Loyalists? If yes, specify.

b) Did any private foundation support research by the Challengers or the Loyalists? If yes, specify.

4) Individuals

a) Did any specific individuals profit directly from the controversy?

b) Were any individuals or groups of individuals accused of profiting indirectly from the controversy?

C) Religious

1) What were the religious issues?

2) Did the Challengers or the Loyalists cite a religious basis for their position?

3) Did any religious groups take a public position in the controversy?

4) Did any religious groups contribute resources to the controversy?

D) Ethical

1) Did the Challengers or the Loyalists attempt to frame the debate within the context of major value debates such as:

a) individual vs. collective rights?

b) liberty vs. equality?

c) progress vs. tradition?

d) sacred vs. secular?

e) patriotism vs. isolationism?

f) other?

2) Were questions of equity raised in the controversy?

3) Were questions of cost — benefit or risk — benefit (see IV.D) raised in the controversy?

VI. Resolution: at the close of the controversy was the challenge characterized:

A) by full response?

B) by co-optation?

C) by preemption?

D) by collapse?

\section{NOTES}

1. Allan Mazur, The Dynamics of Technical Controversies (Communications Press, forthcoming).

2. Dorothy Nelkin, Controversy: The Politics of Technical Decisions. (Beverly Hills, CA: Sage Publications, 1979), p. 7. 
3. See Arthur Caplan, "Methodological issues in the study of controversies in science and technology" (1979). Presented at the 1979 annual meeting of the Society for the Social Studies of Science, Washington, DC.

4. For example, researchers have successfully drawn data from over 150 communities in secondary analyses of the community power literature, testing a variety of propositions relating city types, community structure, and other variables to type of power structure and other output variables. For example, John Walton, "Substance and artifact: The current status of research on community power structure," American Journal of Sociology 71 (1966): 430-438; Roland Warren and Herbert Hyman, "Purposive community changes in consensus and dissensus situations," in Terry Clark, ed., Community Structure and Decision-Making: Comparative Analyses (San Francisco: Chandler, 1968), pp. 404-424; and Claire Gilbert, Community Power Structure (Gainesville, FL: University of Florida Press, 1972).

5. For example, Nelkin, op. cit. (Note 2). A few scholars have begun comparative studies of science-related controversy using very small numbers of cases. For example, Leahy and Mazur have compared movements opposed to nuclear power, fluoridation, and abortion. Peter Leahy and Allan Mazur, "A comparison of movements opposed to nuclear power, fluoridation, and abortion", in Louis Kriesberg, ed., Research in Social Movements, Conflicts and Change. (Greenwich, CT: JAI Press, 1978), pp. 143-154.

6. For a discussion of these problems, see Raoul Narroll, Data Quality Control-A New Research Technique (New York: Free Press, 1962).

7. See William A. Gamson, The Strategy of Social Protest (Homewood, IL: Dorsey Press, 1975).

8. Robert K. Merton, The Sociology of Science: An Episodic Memoir (Carbondale, IL: Southern Illinois University Press, 1979).

9. David Bloor, Knowledge and Social Imagery (London: Routledge and Kegan Paul, 1976).

10. Ibid., p. 5.

11. See Stuart S. Blume, Toward a Political Sociology of Science (New York: Free Press, 1974).

12. Gamson, op. cit. (Note 7).

13. James C. Petersen and Gerald Markle, "Politics and Science in the Laetrile Controversy", Social Studies of Science 9 (1979): 139-66, and Gerald E. Markle and James C. Petersen, Politics, Science and Cancer: The Laetrile Phenomenon (Boulder, CO: Westview Press, 1980).

14. James C. Petersen, "Expansion of conflict in cancer controversies," (1980). Presented at the 1980 annual meeting of the American Association for the Advancement of Science, San Francisco, CA.

15. Gamson, op. cit. (Note 7).

16. See Gerald E. Markle and James C. Petersen, "Resolution of the Laetrile Controversy: past attempts and future prospects," (1979). Presented at a session in the project "Elements and Principles of Closure in Ethical and Scientific Disputes," The Hastings Center, Hastings-on-Hudson, New York. Copies available from the authors.

17. Petersen and Markle (1979), op. cit. (Note 13).

18. Gamson, op. cit., (Note 7), p. 28. 